\title{
Characterization and Classification of Groundwater from Wells Using an Electronic Tongue (Kairouan, Tunisia)
}

\author{
Khawla Sghaier $^{1}$, Houcine Barhoumi ${ }^{{ }^{*}}$, Abderrazak Maaref ${ }^{1}$, Maryam Siadat $^{2}$, \\ Nicole Jaffrezic-Renault ${ }^{3}$ \\ ${ }^{1}$ Laboratory of Physics and Chemistry of Interfaces, University of Monastir, Monastir, Tunisia \\ ${ }^{2}$ Laboratory of Interfaces, Sensors and Microelectronics, University of Metz, Metz, France \\ ${ }^{3}$ Laboratory of Analytical Sciences, University of Claude Bernard-Lyon1, Villeurbanne Cedex, France \\ E-mail: Houcine.Barhoumi@fsm.rnu.tn
}

Received January 17, 2011; revised April 12, 2011; accepted May 22, 2011

\begin{abstract}
A sensor array comprising 9 potentiometric chemical sensors and some pattern recognition tools for the data processing has been applied in order to characterize the groundwater in the plain of Kairouan Region (Tunisia). A total of 17 groundwater samples were collected from three different villages and analyzed for their chemical components. Nine chemical parameters were determined: Potassium, Sodium, Calcium, Ammonium, Cadmium, Chlorides, Nitrates, Fluoride and pH. Multi-sensor responses measured in each water sample were diagnosed by Principal Component Analysis (PCA) and Cluster Analysis (CA). PCA is a procedure for reducing data redundancy. CA is used to detect spatial similarity among sampling sites. This methodology is simple, rapid and the obtained results demonstrate that the electronic tongue technique based on the sensor array combined with pattern recognition method could be a useful tool for the characterization and the classification of wells water samples.
\end{abstract}

Keywords: Electronic Tongue, Groundwater, Pattern Recognition Tools, PCA, CA

\section{Introduction}

Groundwater originates from the deep infiltration of rain and surface water. In general terms groundwater flows slowly through geologic formations and remains in contact with minerals often isolated from the atmosphere. The quality parameters of groundwater are a matter of serious concern today, which represents a critical point to be evaluated. These parameters aim at human consumption and irrigation or industrial use. It is very necessary to make a constant monitoring of water qualities for the protection of the natural environment as well as for the public well-being. Therefore it is worthwhile to use an appropriate control system able to point out any variation occurring in the water characteristics. When combined with chemometric techniques, these chemical sensors arrays are called electronic tongue.

Chemometric methods, namely, cluster analysis (CA), principal component analysis (PCA), factor analysis (FA) and discriminate analysis (DA), are highly increasing in their use. They have been applied to the analysis of environmental data, such as water samples from lakes and rivers [1]. Some examples of PCA and CA applications in environmental practices are described below.

Multivariate statistical techniques, CA and PCA were applied to the data on water quality of Manchar Lake in Pakistan [2]. This was done to characterize and evaluate surface and freshwater quality, which is useful in verifying temporal and spatial variations caused by natural and anthropogenic factors linked to seasonality $[3,4]$. Shrestha et al. applied the PCA and CA techniques for the evaluation of temporal/spatial variations and the interpretation of a large complex water quality data set of the Fuji river basin [5]. In addition, the CA technique has been used for the characterization of the groundwater system of the southern plain of Friuli-Venezia Giulia Region (Italy) on the basis of its physico-chemical composition. This was to detect mul- tivariate patterns for unpolluted waters typical of specific areas in the plain, as well as for eventual polluted zones [6]. These studies 
have provided good examples of the effective application of PCA and CA methods.

In recent years, the PCA and CA techniques have been applied to a variety of environmental issues, including evaluation of the monitoring of groundwater wells. For example, Simeonov et al. show a very comprehensive description of multivariate statistical assessment of water quality of northern Greece based on the evaluation of a large and complex database [7].

This present work aims at the characterization of well waters collected from three villages in Kairouan plain devoted to intensive agricultural practices, animal and human needs. In each sample nine chemical parameters were determined such as Calcium, Sodium, Potassium, Ammonium, Cadmium, Fluoride, Chloride, Nitrate and $\mathrm{pH}$ which are commonly used for defining the water quality. The experimental data obtained from the sensor array applied for the different water samples analysis are treated using pattern recognition techniques, such as the PCA and CA.

\section{Materials and Methods}

\subsection{Sampling}

The Kairouan plain involves more than $3000 \mathrm{~km}^{2}$ and represents the most important part in the semi-arid central zone of Tunisia, with more than 5,000 shallow wells and more than 150 boreholes. This area is devoted to intensive agricultural practices and the groundwater is heavily used for irrigation and for domestic use. The analytical data are relative to 17 domestic wells with depth ranging from 40 to $140 \mathrm{~m}$. The geographical distribution of the villages in which wells are located is represented in Figure 1.

The number of sampling wells in their territory is as follows: six wells located in Hadjeb el Aioun, six wells in Chebika and five wells in Sidi Amor Bou Hadjila. All water samples were taken in autumn (October-November 2009) using polyethylene bottles and were analyzed as soon as possible.

\subsection{Chemical Sensor Array}

Experimental measurements were performed with an electronic tongue system comprising 9 ion-selective electrodes (ELIT electrodes-NICO 2000 Ltd and Metrohm electrodes) and an $\mathrm{Ag} / \mathrm{AgCl}$ reference electrode. The sensors and their attributes are shown in Table 1.

The Potentiometric measurements were performed thanks to an Ion-Analyser ELIT 9808 (8-Channel IonAnalyser) which is a powerful tool for measuring and monitoring ion concentrations. The Ion-Analyser is re- quired to convert the electrical signal from the ion sensitive electrode into a relevant unit of concentration (ppm or $\mathrm{mol} \cdot \mathrm{L}^{-1}$ ). The electronic tongue architecture is shown in Figure 2. The principle of the method is to detect the changes in the voltage $(\mathrm{mV})$ intensity between the chemical sensors (Working Electrodes) and the $\mathrm{Ag} / \mathrm{AgCl}$ Reference Electrode (RE).

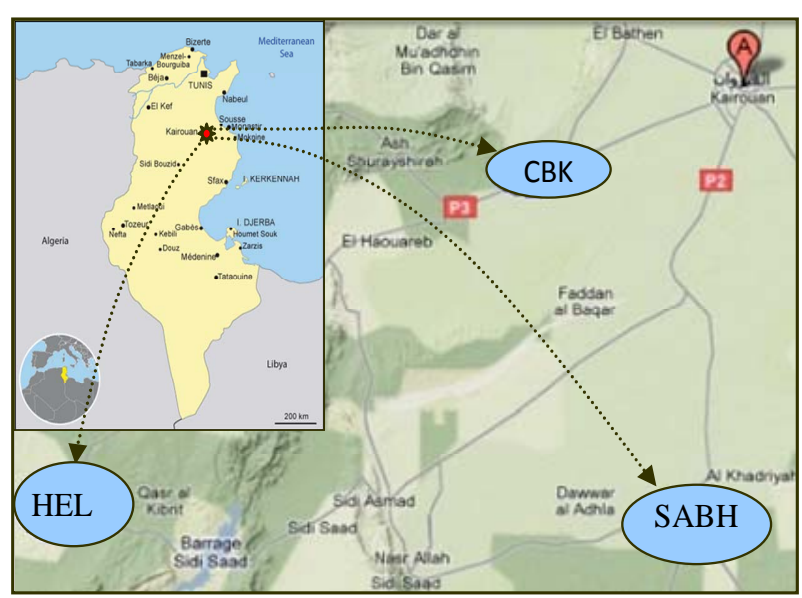

Figure 1. Map of study area in which wells are located.

Table 1. Response feature of the sensor array.

\begin{tabular}{cccc}
\hline $\begin{array}{c}\mathrm{N}^{\circ} \text { in } \\
\text { array }\end{array}$ & Electrode & Membrane & $\begin{array}{c}\text { Concentration } \\
\text { Range }(\mathrm{mol} / \mathrm{L})\end{array}$ \\
\hline 1 & Potassium & PVC & $10^{-5}-1$ \\
2 & Calcium & PVC & $5 \cdot 10^{-7}-1$ \\
3 & Sodium & PVC & $2 \cdot 10^{-6}-0.9$ \\
4 & Ammonium & PVC & $2 \cdot 10^{-6}-5 \cdot 10^{-1}$ \\
5 & Cadmium & Crystal & $\left.9 \cdot 10^{-7}-0.1\right)$ \\
6 & Chloride & Crystal & $5 \cdot 10^{-5}-1$ \\
7 & Fluoride & Crystal & $10^{-6}-1$ \\
8 & Nitrate & PVC & $5 \cdot 10^{-6}-1$ \\
9 & Ag/AgCl & - & - \\
\hline
\end{tabular}

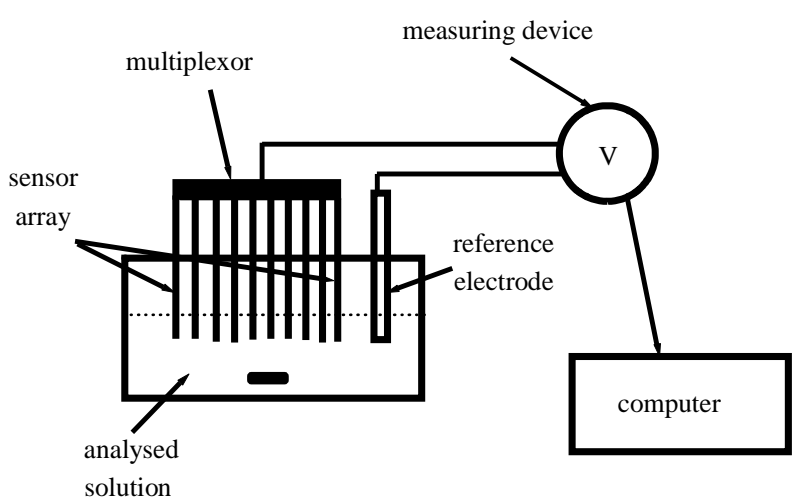

Figure 2. Chemical multi-sensor array used as an "elec tronic tongue". 
The typical responses of two sensors for ions detection in water sample are shown in Figure $\mathbf{3}$ as an example. Each curve represents a different potential sensor response in function with time (min).

\subsection{The Dataset and Statistical Procedures}

In this study 9 chemical parameters have been deduced from the characterized water samples collected from 17 wells. The data matrix based on the chemical parameters is subjected to different multivariate statistical techniques CA and PCA in order to examine the relationships between variables (such as chemical parameters in groundwater), to extract the information about the similarities or dissimilarities between sampling sites, to classify the well water in clusters and to identify the important discriminant variables. Statistical computations were executed using the statistical software package, SPSS 11.0. The multivariate methods utilized are summarized below.

\subsubsection{Dataset}

Data were organized into a matrix of 17 rows (well waters) x 8 columns (chemical parameters). The output data is treated subsequently with some kind of a multivariate analysis technique. Chemometrics make use of multivariate methods to analyze a large amount of chemical data. These methods extract information from data and produce a model that attempts to describe the reality. Chemometric methods-also known as multivariate statistical techniques-are enjoying in the last years a high scientific interest and are now routinely used in most fields of application [8-10]. Chemometric methods identify the natural clustering pattern and group variables on the basis of similarities between the samples. The most common chemometric methods for classification are namely, cluster analysis (CA) and principal component analysis (PCA) which were applied to the multi-sensor output data sets. These multidimensional data analysis methods are becoming very popular in environmental studies dealing with measurements and monitoring [11].

\subsubsection{Principal Components Analysis (PCA)}

Principal component analysis is a technique widely used for reducing the dimensions of multivariate problems [12]. PCA provides an objective way of finding indices of this type so that the variation in the data can be accounted for as concisely as possible [13]. PCA provides information on the most meaningful parameters which describe the whole data set interpretation, data reduction and to summarize the statistical correlation among constituent in the water with minimum loss of original information [3].

\subsubsection{Cluster Analysis (CA)}

The CA technique is an unsupervised classification procedure that can be applied to data that exhibit "natural" grouping. The procedure involves measuring either the difference or the similarity between the objects to be clustered. The resulting clusters of objects should then exhibit high internal (within cluster) homogeneity and high external (between clusters) heterogeneity. Hierarchical agglomerative clustering is the most common approach, which provides instinctive similarity relationships

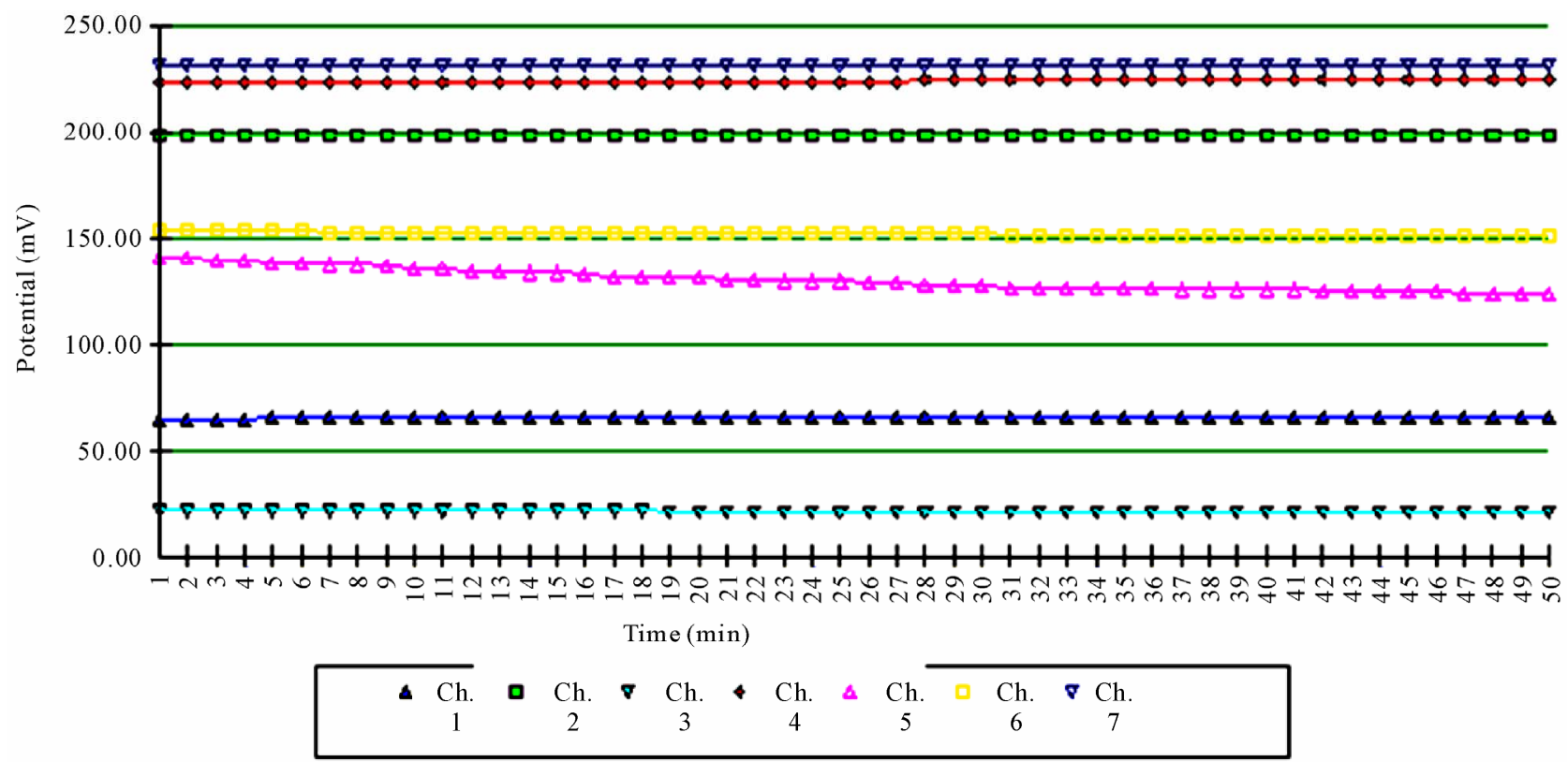

Figure 3. Responses of seven sensors of the electronic tongue in water samples. 
between any other sample and the entire data set, and is typically illustrated by a dendrogram [14]. The dendrogram provides a visual summary of the clus- tering processes, presenting a picture of the groups and their proximity, with a dramatic reduction in dimension- ality of the original data. The Euclidean distance usually gives the similarity between two samples and this distance can be represented by the difference between analytical values from the samples [15]. Many applications of CA to water quality assessment have been reported [16-19]. In this study, hierarchical agglomerative CA was performed on the normalized data set by means of the Ward's method, using squared Euclidean distances as a measure of simi- larity.

\section{Results and Discussion}

\subsection{Chemical Parameter Features of the Ground Water Wells}

The following chemical parameters were determined such as Potassium $\left(\mathrm{K}^{+}\right)$, Sodium $\left(\mathrm{Na}^{+}\right)$, calcium $\left(\mathrm{Ca}^{2+}\right)$, Ammonium $\left(\mathrm{NH}_{4}^{+}\right)$, Cadmium $\left(\mathrm{Cd}^{2+}\right)$, chloride $\left(\mathrm{Cl}^{-}\right)$, nitrate $\left(\mathrm{NO}_{3}^{-}\right)$, Fluoride $\left(\mathrm{F}^{-}\right)$and $\mathrm{pH}$ as an illustration. The values of these parameters are plotted together in Figure 4.

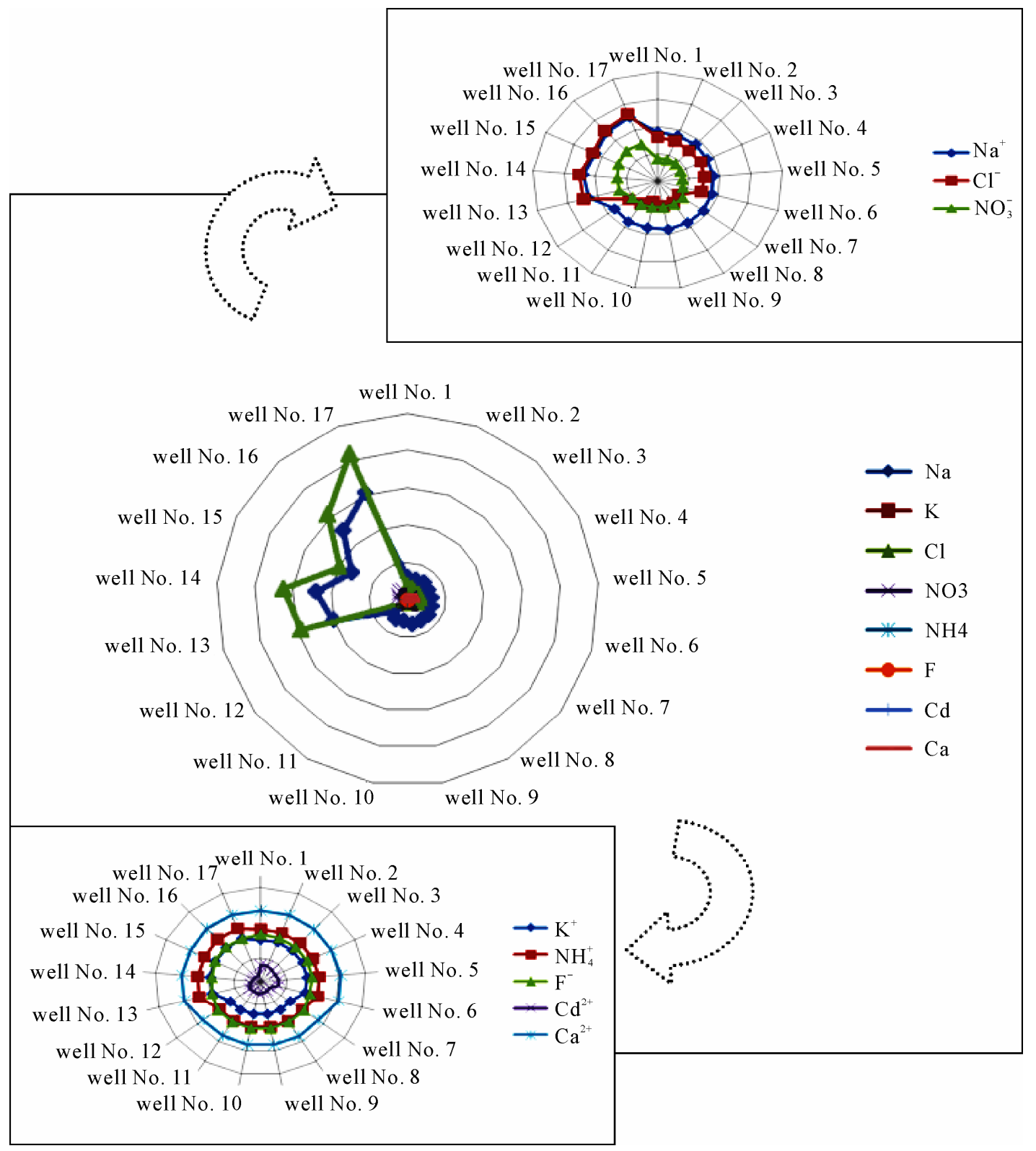

Figure 4. Radar plot of the content (in mol/l) of $\mathrm{K}^{+}, \mathrm{NH}_{4}^{+}, \mathrm{Cl}^{-}, \mathrm{Na}^{+}, \mathrm{F}^{-}, \mathrm{Cd}^{2+}, \mathrm{Ca}^{2+}$ and $\mathrm{NO}_{3}^{-}$in 17 well water samples. 
The minimum and maximum values of all chemical parameters of water samples collected from three sampling villages are presented in Table 2 . The results are compared to the values of the World Health recommended maximum permissible limits [20]. The values that go beyond the permissible limits are high-lighted. The $\mathrm{pH}$ value is related to the amount of hydrogen/hydroxide ions in water. The $\mathrm{pH}$ in water samples ranged from 7 to 7.74 . During the autumn season, the $\mathrm{pH}$ trend shows minor variation.

The amount of $\mathrm{Na}^{+}$and $\mathrm{Cl}^{-}$in water wells was found to be the highest in Sidi Amor village that lie in a plain exposed to agricultural pollution. This amount exceeded the values proposed by WHO water quality standards. Sodium concentrations in water samples ranged from $380 \mathrm{mg} / \mathrm{l}$ to $786 \mathrm{mg} / \mathrm{l}$, which was higher than permissible limit $(200 \mathrm{mg} / \mathrm{l})$. According to Versari et al. chloride concentrations higher than $200 \mathrm{mg} / \mathrm{l}$ are considered to be a risk for human health and may cause unpleasant taste of water [21].

It has been reported that high consumption of salts, $\mathrm{NaCl}$ in particular, may be crucial for the development of essential hypertension, may increase the risk for stroke, left ventricular hypertrophy, osteoporosis, renal stones and asthma [22]. However, McCarthy (Entry et Farmer, 2001) also points out that the salt restrictions may evoke detrimental counter-regulatory metabolic responses such as increased production of rennin and angiotensin II together with increased sympathetic activity that are potentially inimical to vascular health.

The levels of $\mathrm{NO}_{3}^{-}$were found to be higher in Sidi omor water analysis (average $150 \mathrm{mg} / \mathrm{l}$ ), which are mostly higher than permissible limit of drinking water by WHO guidelines $(50 \mathrm{mg} / \mathrm{l})$, indicating pollution in this region. Most cases of nitrate contamination in groundwater depend upon climate, differences in soil, fertilizer application, irrigation practices, and farming systems. The main source of nitrate pollution in water wells of Sidi Amor Bou Hadjila (that situated adjacent to farm fields) results from agriculture and the actions of farmers. High nitrate concentrations ( $>50 \mathrm{mg} / \mathrm{l}$ ) can cause "bluebaby" syndrome (a condition that prevents blood from carrying oxygen) and has been tentatively linked to increased rates of stomach cancer, birth defects, miscarriage, leukemia, Non-Hodgkin's lymphoma, reduced body growth and slower reflexes, and increased thyroid size [23].

The concentrations of $\mathrm{Cd}^{2+}$ were found to be very low $(<0.01 \mathrm{mg} / \mathrm{l})$ in water samples collected from different villages. Elevated concentrations of $\mathrm{Cd}^{2+}$ can cause nausea, vomiting, salivation and renal failure as well as kidney, liver and blood damages [24]. Saleh et al. suggested that high concentrations of $\mathrm{Cd}^{2+}$ may even cause muta- tions [25].

The $\mathrm{K}^{+}$concentration was less than permissible limit (12 mg/l) in all water samples. Moreover $\mathrm{Ca}^{2+}$ concentration was below the optimum $(100 \mathrm{mg} / \mathrm{l})$ level in all the samples studied. Sodium is considered as a contributory cause of dietary cancer, whereas potassium may play a protective role [26]. The effect of calcium is less clear as it may depend on the concentration of both sodium and potassium [27].

The results revealed that the quality of well water of Sidi Amor village is out of limited; according to the WHO standards, which can be used for drinking by humans only after prior treatment.

\subsection{Multivariate Analysis}

Several pattern recognition methods such as PCA and CA were applied to the multi-sensor output data sets. PCA can only be used as an unsupervised pattern recognition method; this behavior can indicate the data trend in a visualizing dimension (i.e., 1-dimension, 2-dimension or 3-dimension) space.

In this research work PCA was applied to summarize the statistical correlation among components in the water samples. Concentration order among all chemical parameters differs greatly and the statistical results should be highly biased by any parameter with high concentration. The result of the PCA based on the correlation matrix of chemical components is expressed in Table $\mathbf{3}$ and showed the high interdependence between particular variables such as $\mathrm{Na}^{+}$which was highly correlated with $\mathrm{Cl}^{-}, \mathrm{K}^{+}, \mathrm{NO}_{3}^{-}$, and $\mathrm{NH}_{4}^{+}$.

On the basis of the score-plot (Figure 5) most of the information is gathered in the first two significant factors (96.2\%). Their loadings are presented in the Table 4 and correspond to the correlation coefficient of a particular variable. Factor 1, with the highest grouping power, is highly correlated to chemical parameters: $\mathrm{K}^{+}, \mathrm{NH}_{4}^{+}, \mathrm{Cl}^{-}$, $\mathrm{Na}^{+}$and $\mathrm{NO}_{3}^{-}$. In our case we have only considered the two first principal components, PC1 and PC2, which explains $96.2 \%$ of total variance in the data set ( 9 variables) of groundwater. The first component (PC1) accounts for over $67.4 \%$ of the total variance in the data set of the well water samples, and the second component (PC2) explains $28.8 \%$ of the total variance.

Figures 6(a) and 6(b) show respectively the loading and score plots for PC1 and PC2. From the interpretation of these Figures we can deduce the pattern of behavior of the chemical elements. Figure 6(a) shows the behavior of the variables (chemical parameters). As it can be seen, there is an association of $\mathrm{K}^{+}, \mathrm{NH}_{4}^{+}, \mathrm{Cl}^{-}, \mathrm{Na}^{+}$and $\mathrm{NO}_{3}^{-}$, and in a less extension $\mathrm{pH}$. These elements behave in an 
Table 2. Ranges of the total concentrations of the nine chemical species in water samples. $\mathbf{p H}$ in $\mathbf{p H}-\mathrm{units}, \mathrm{F}^{-}$to $\mathrm{NH}_{4}^{+}$in $\mathbf{m g} / \mathrm{l}$.

\begin{tabular}{ccccc}
\hline & WHO limits & Chebika & Hadjeb el Aioun & Sidi Amor Bou Hadjila \\
\hline $\mathrm{pH}$ & $6.5-8.5$ & $7.06-7.17$ & $7.49-7.56$ & $6.99-7.74$ \\
$\mathrm{~F}^{-}$ & 1.5 & $0.15-0.19$ & $0.22-0.23$ & $0.1-0.24$ \\
$\mathrm{Cl}^{-}$ & $\mathbf{2 5 0}$ & $99-140$ & $21-49$ & $\mathbf{7 0 5 - 1 9 3 2}$ \\
$\mathrm{Na}^{+}$ & $\mathbf{2 0 0}$ & $132-146$ & $122-155$ & $\mathbf{3 7 9 - \mathbf { 7 8 6 }}$ \\
$\mathrm{NO}_{3}^{-}$ & $\mathbf{5 0}$ & $39-43$ & $58-62$ & $\mathbf{1 1 7 - \mathbf { 1 8 8 }}$ \\
$\mathrm{K}^{+}$ & 12 & $0.13-0.15$ & $0.026-0.029$ & $0.22-0.32$ \\
$\mathrm{Ca}^{2+}$ & 100 & $40-57$ & $12.34-13.66$ & $36-52$ \\
$\mathrm{Cd}^{2+}$ & 3 & $0.002-0.003$ & $0.0008-0.001$ & $0.0003-0.001$ \\
$\mathrm{NH}_{4}^{+}$ & - & $0.48-0.54$ & $0.15-0.17$ & $1.04-1.31$ \\
\hline
\end{tabular}

Table 3. Correlation matrix of mineral water variables (17 samples $\times 9$ variables).

\begin{tabular}{cccccccccc}
\hline & $\mathbf{N a}$ & $\mathbf{K}$ & $\mathbf{C l}$ & $\mathbf{N O}_{3}$ & $\mathbf{p H}$ & $\mathbf{N H}_{4}$ & $\mathbf{F}$ & $\mathbf{C d}$ & $\mathbf{C a}$ \\
\hline $\mathbf{N a}$ & 1.00 & & & & & & & & \\
$\mathbf{K}$ & $\mathbf{0 . 8 4}$ & 1.00 & & & & & & & \\
$\mathbf{C l}$ & $\mathbf{0 . 9 9}$ & $\mathbf{0 . 8 8}$ & 1.00 & & & & & & \\
$\mathbf{N O}_{3}$ & $\mathbf{0 . 9 2}$ & $\mathbf{0 . 7 7}$ & $\mathbf{0 . 9 0}$ & 1.00 & & & & & \\
$\mathbf{p H}$ & 0.62 & 0.24 & 0.56 & 0.76 & 1.00 & & & & \\
$\mathbf{N H}$ & $\mathbf{0 . 9 0}$ & $\mathbf{0 . 9 7}$ & $\mathbf{0 . 9 4}$ & $\mathbf{0 . 8 2}$ & 0.37 & 1.00 & & & \\
$\mathbf{F}$ & -0.64 & -0.87 & -0.71 & -0.47 & 0.01 & -0.85 & 1.00 & & \\
$\mathbf{C d}$ & -0.66 & -0.28 & -0.60 & -0.77 & -0.97 & -0.38 & 0.01 & 1.00 & \\
$\mathbf{C a}$ & 0.40 & 0.75 & 0.47 & 0.23 & -0.38 & 0.68 & -0.82 & 0.38 & 1.00 \\
\hline
\end{tabular}

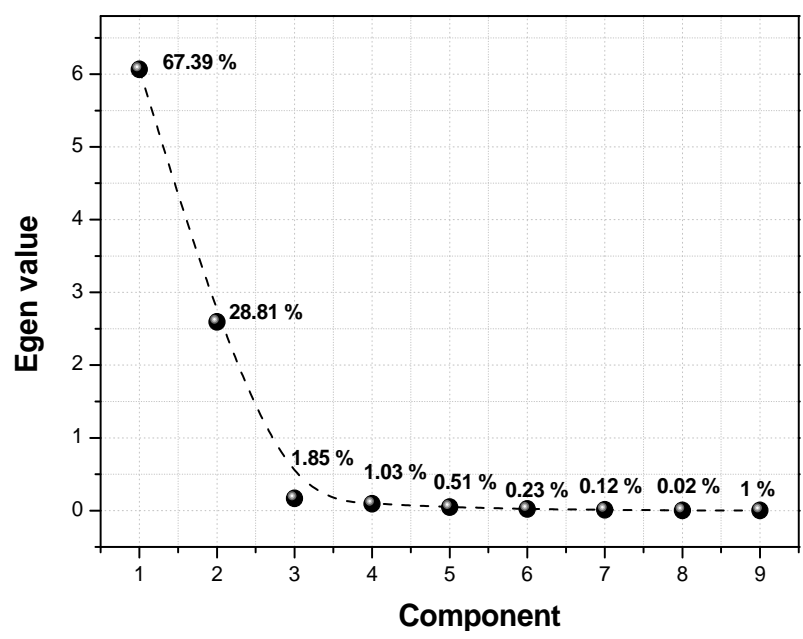

Figure 5. Score-plot for the principal component model of the monitoring data.

opposite way to $\mathrm{Cd}^{2+}$ and $\mathrm{F}^{-}, \mathrm{Ca}^{2+}$ appear more dispersed into the components space, showing a more individualized behavior. For visualizing cluster trend of 17 well water samples, a 2-dimension scatter plot using the top two principal components score vectors (i.e., PC1, PC2) is obtained, in Figure 6(b). We find a clear cluster trend for the three sampling villages in this 2-dimension space.

In general, the wells corresponding to different towns are clustered in different regions of the components space, so the differential behavior of the fractions is clearly demonstrated.

The superposition of the loading and score plots of Figure 6 shows that the sample wells No. 13, 14, 15, 16 and 17 were all characterized by high content of $\mathrm{K}^{+}$, $\mathrm{NH}_{4}^{+}, \mathrm{Cl}^{-}, \mathrm{Na}^{+}$and $\mathrm{NO}_{3}^{-}$. The 17 well waters with low-mineral content were grouped on the right side of the plot (circled). Continuous circles inscribe wells belonging to the same cluster.

The redundancy of information suggests applying the CA in order to reduce the dimensionality of dataset as it was done in PCA. Cluster analysis groups the objects (cases) into classes (clusters) on the basis of similarities within a class and dissimilarities between different classes. In this study, cluster analysis was used to detect the similarity groups between well water samples. The dendrogram grouping all the 17 wells into three statistically significant clusters (groups) is presented in the Figure 7. Cluster I is formed by wells No. 1, 2, 3, 4, 5, and 6, cluster 
Table 4. Matrix of factor loading obtained for the well waters

\begin{tabular}{ccc}
\hline Parameters & F1 & F2 \\
\hline $\mathrm{Cl}^{-}$ & 0.984 & $-4.239 \mathrm{E}-02$ \\
$\mathrm{Na}^{+}$ & 0.975 & -0.127 \\
$\mathrm{NH}_{4}^{+}$ & 0.970 & 0.215 \\
$\mathrm{~K}^{+}$ & 0.931 & 0.326 \\
$\mathrm{NO}_{3}^{-}$ & 0.920 & -0.317 \\
$\mathrm{~F}^{-}$ & -0.759 & -0.563 \\
$\mathrm{Ca}^{2+}$ & 0,521 & 0.836 \\
$\mathrm{pH}^{2+}$ & 0.555 & -0.813 \\
$\mathrm{Cd}^{2+}$ & -0.581 & 0.803 \\
\hline
\end{tabular}

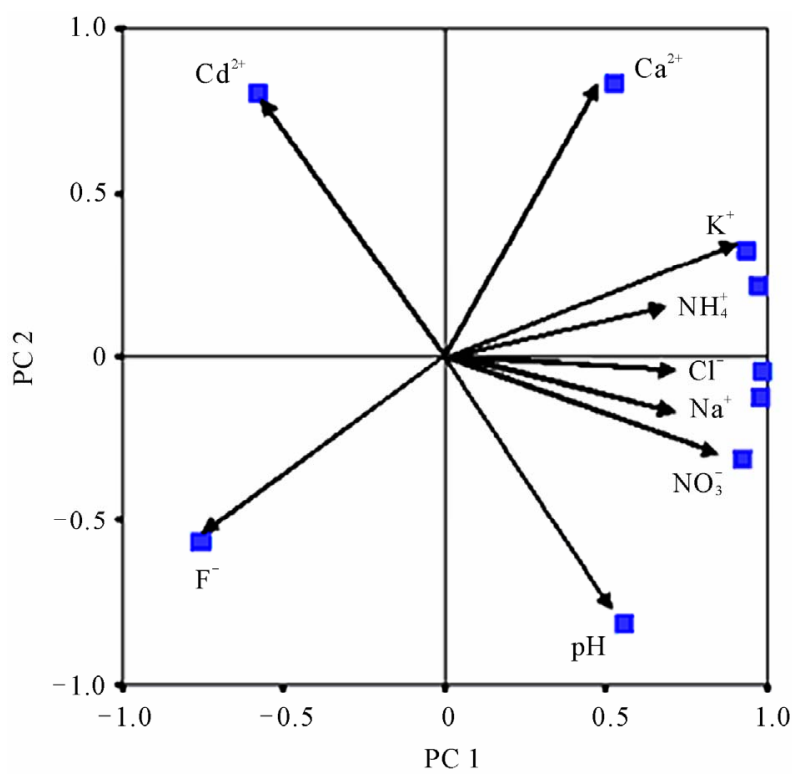

(a)

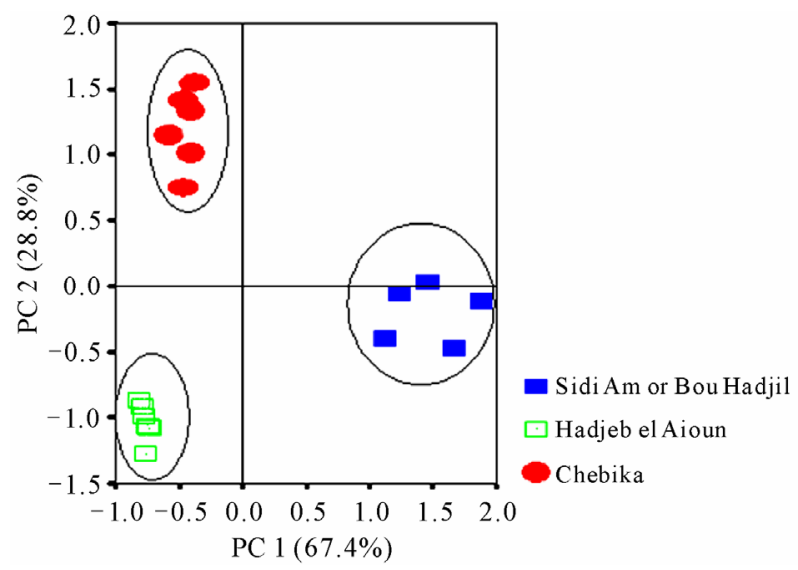

(b)

Figure 6. Representation of the PC scores on the first two components for the Kairouan well waters. Waters with high-mineral content are located within the ellipse. (a) Loading plot of variables; (b) score plot of observations.

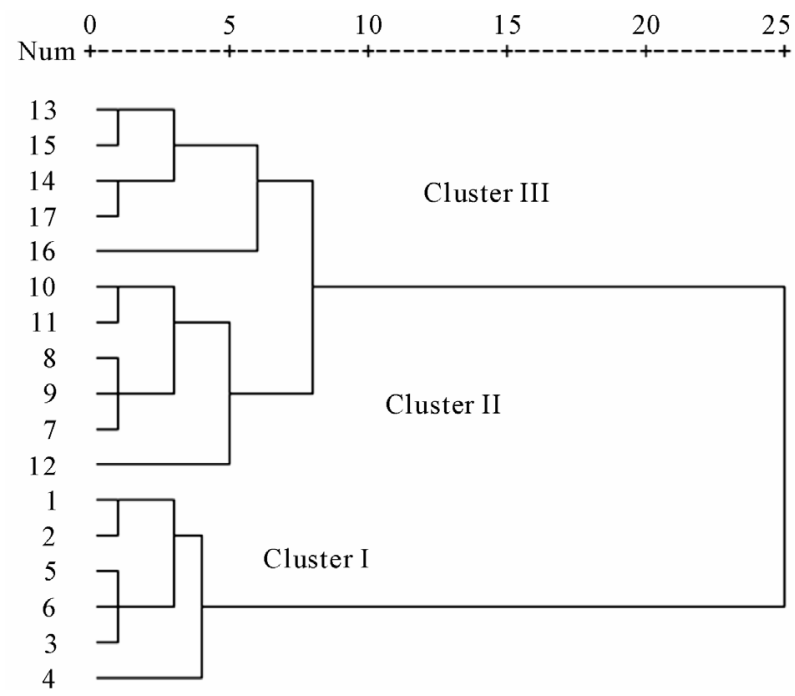

Figure 7. Dendrogram showing clustering of groundwater. Each cluster indicates groups of similar physico-chemistry.

II by wells No. 7, 8, 9, 10, 11, 12, and finally cluster III by wells $13,14,15,16,17$. It is clearly seen that cluster III is characterized by the biggest Euclidean distance among the other clusters (high significance of clustering). This cluster corresponds to wells situated relatively in Sidi Amor Bou Hadjila village. The results indicate that the CA technique is useful in offering reli- able classification of well waters. There are other reports where similar approach has successfully been applied to water quality programs $[4,7]$.

\section{Conclusions}

The electronic tongue on the basis of the array of 9 ionselective electrodes and pattern recognition techniques for the data processing was employed to qualitative analysis in order to characterize and to classify groundwater samples collected from kairouan plain. It can be concluded that the multivariate statistical techniques such as PCA and CA are a powerful tools for the classification of a series of well waters as function of their chemical composition. This approach of using a chemical multi-sensor array sensitive to various species might also be a viable option to distinguish different water resources.

\section{Acknowledgements}

This work was supported by EGIDE through UTIQUE program No 09G 1128.

\section{References}

[1] M. Felipe-Sotelo, J. M. Andrade, A. Carlosena and R. 
Tauler, "Temporal Characterisation of River Waters in Urban and Semi-Urban Areas Using Physico-Chemical Parameters and Chemometric Methods," Analytica Chimica Acta, Vol. 583, No. 1, 2007, pp. 128-137. doi:10.1016/j.aca.2006.10.011

[2] T. G. Kazi, M. B. Arain, M. K. Jamali, N. Jalbani, H. I. Afridi, R. A. Sarfraz, J. A. Baig and A. Q. Shah, "Assessment of Water Quality of Polluted Lake Using Multivariate Statistical Techniques: A Case Study,” Ecotoxicology and Environmental Safety, Vol. 72, No. 2, 2009, pp. 301-309. doi:10.1016/j.ecoenv.2008.02.024

[3] B. Helena, R. Pardo, M. Vega, E. Barrado, J. M. Fernandez and L. Fernandez, "Temporal Evolution of Groundwater Composition in an Alluvial Aquifer (Pisuerga River, Spain) by Principal Component Analysis," Water Research, Vol. 34, No. 3, 2000, pp. 807-816. doi:10.1016/S0043-1354(99)00225-0

[4] K. P. Singh, A. Malik, D. Mohan and S. Sinha, "Multivariate Statistical Techniques for the Evaluation of Spatial and Temporal Variations in Water Quality of Gomti River (India): A Case Study,” Water Research, Vol. 38, No. 18, 2004, pp. 3980-3992. doi:10.1016/j.watres.2004.06.011

[5] S. Shrestha and F. Kazama, "Assessment of Surface Water Quality Using Multivariate Statistical Techniques: A Case Study of the Fuji River Basin, Japan,” Environmental Modelling and Software, Vol. 22, No. 4, 2007, pp. 464-475. doi:10.1016/j.envsoft.2006.02.001

[6] P. Barbieri, G. Adamia, A. Favretto, A. Lutmanc, W. Avoscan and E. Reisenhofer, "Robust Cluster Analysis for Detecting Physico-Chemical Typologies of Freshwater from Wells of the Plain of Friuli (Northeastern Italy)," Analytica Chimica Acta, Vol. 440, No. 2, 2001, pp. 161170. doi:10.1016/S0003-2670(01)00991-6

[7] V. Simeonov, J. A. Stratis, C. Samara, G. Zachariadis, D. Voutsa, A. Anthemidis, M. Sofoniou and T. Kouimtzis, "Assessment of the Surface Water Quality in Northern Greece,” Water Research, Vol. 37, No. 17, 2003, pp. 4119-4124. doi:10.1016/S0043-1354(03)00398-1

[8] H. Martens and T. Naes, "Multivariate Calibration,” Wiley, Chichester, 1989.

[9] D. Massart, B. Vandeginste, L. Buydens, S. De Jong, P. Lewi and J. Smeyers-Verbeke, "Handbook of Chemometrics and Qualimetrics,” Elsevier, Amsterdam, 1998.

[10] R. G. Brereton, "Chemometrics: Data Analysis for the Laboratory and Chemical Plant," Wiley, Chichester, 2003.

[11] T. Kowalkowski, R. Zbytniewski, J. Szpejna and B. Buszewski, "Application of Chemometrics in River Water Classification,” Water Research, Vol. 40, No. 4, 2006, pp. 744-752. doi:10.1016/j.watres.2005.11.042

[12] R. A. Johnson and D. W. Wichern, "Applied Multivariate Statistical Analysis," Prentice Hall, Englewood Cliffs, 1992.

[13] C. Sarbu and H. F. Pop, "Principal Component Analysis Versus Fuzzy Principal = Component Analysis. A Case Study: The Quality of Danube water (1985-1996)," Talanta, Vol. 65, No. 5, 2005, pp. 1215-1220. doi:10.1016/j.talanta.2004.08.047

[14] J. E. McKenna Jr, “An Enhanced Cluster Analysis Program with Bootstrap Significance Testing for Ecological Community Analysis,” Environmental Modelling Software, Vol. 18, No. 3, 2003, pp. 205-220. doi:10.1016/S1364-8152(02)00094-4

[15] M. Otto, "Multivariate Methods,” In: R. Kellner, J. M. Mermet, M. Otto and H. M Widmer, Eds., Analytical Chemistry, Wiley VCH, Weinheim, 1998, p. 916.

[16] M. Vega, R. Pardo, E. Barrado and L. Deban, “Assessment of Seasonal and Polluting Effects on the Quality of River Water by Exploratory Data Analysis," Water Research, Vol. 32, No. 12, 1998, pp. 3581-3592. doi:10.1016/S0043-1354(98)00138-9

[17] S. Adams, R. Titus, K. Pietesen, G. Tredoux and C. Harris, "Hydrochemical Characteristic of Aquifers near Sutherland in the Western Karoo, South Africa," Journal of Hydrology, Vol. 241, No. 1-2, 2001, pp. 91-103. doi:10.1016/S0022-1694(00)00370-X

[18] D. A. Wunderlin, M. P. Diaz, M. V. Ame, S. F. Pesce, A. C. Hued and M. A. Bistoni, "Pattern Recognition Techniques for the Evaluation of Spatial and Temporal Variations in Water Quality. A Case Study: Suquia River Basin (Cordoba, Argentina)," Water Research, Vol. 35, No. 12, 2001, pp. 2881-2894. doi:10.1016/S0043-1354(00)00592-3

[19] R. Reghunath, T. R. J. Murthy and B. R. Raghavan, “The Utility of Multivariate Statistical Techniques in Hydrogeochemical Studies: An Example from Karnataka, India,” Water Research, Vol. 36, No. 10, 2002, pp. 24372442. doi:10.1016/S0043-1354(01)00490-0

[20] WHO, "Guidelines for Drinking-Water Quality,” 3rd Edition, WHO, Geneva, 2004.

[21] A. Versari, G. P. Parpinello and S. Galassi, "Chemometric Survey of Italian Bottled Mineral Waters by Means of Their Labelled Physicochemical and Chemical Composition," Journal of Food Composition and Analysis, Vol. 15, No. 3, 2002, pp. 251-264. doi:10.1006/jfca.2002.1058

[22] M.F. McCarthy, "Should We Restrict Chloride Rather than Sodium,” Medical Hypotheses, Vol. 63, No. 1, 2004, pp. 138-148. doi:10.1016/j.mehy.2003.11.005

[23] J. A. Entry and N. Farmer, "Ground Water Quality: Movement of Coliform Bacteria and Nutrients in Groundwater Flowing Through Basalt and Sand Aquifers,” Journal of Environmental Quality, Vol. 30, No. 5, 2001, pp. 1533-1539.

[24] A. Ikem, S. Odueyungbo, N. O. Egiebor and K. Nyavor "Chemical Quality of Bottled Waters from Three Cities in Eastern Alabama," The Science of the Total Environment, Vol. 285, No. 1-3, 2002, pp. 165-175. doi:10.1016/S0048-9697(01)00915-9

[25] M. A, Saleh, E. Ewane, J. Jones and B. L. Wilson, "Chemical Evaluation of Commercial Bottled Drinking Water from Egypt,” Journal of Food Composition and Analysis, Vol. 14, No. 2, 2001, pp. 127-152. doi:10.1006/jfca.2000.0858

[26] B. Jansson, "Potassium, Sodium, and Cancer: A Review,” 
Journal of Environmental Pathology, Toxicology and Oncology, Vol. 15, No. 2-4, 1996, pp. 65-73.

[27] C. Y. Yang, H. F. Chiu, J. F. Chiu, S. S. Tsai and M. F.
Cheng, "Calcium and Magnesium in Drinking Water and Risk of Death from Colon Cancer," Japanese Journal of Cancer Research, Vol. 88, No. 10, 1997, pp. 928-933. 